\title{
THREE-DIMENSIONAL WOODY VEGETATION STRUCTURE ACROSS DIFFERENT LAND-USE TYPES AND -LAND-USE INTENSITIES IN A SEMI-ARID SAVANNA
}

\author{
Jolene Fisher $^{\mathrm{a}, \mathrm{b}}$, B.F.N. Erasmus ${ }^{\mathrm{a}}$, Ed Witkowski ${ }^{\mathrm{a}}$, Jan van Aardt ${ }^{\mathrm{c}}$,Greg Asner ${ }^{\mathrm{d}}$, Ty Kennedy-Bowdoin ${ }^{\mathrm{d}}$, Dave \\ Knapp $^{\mathrm{d}}$, Renaud Mathieu ${ }^{\mathrm{b}}$ and Konrad Wessels ${ }^{\mathrm{e}}$ \\ ${ }^{\text {a }}$ School of Animal, Plant and Environmental Science, University of the Witwatersrand \\ ${ }^{\mathrm{b}}$ Natural Resources in the Environment, Council for Scientific and Industrial Research \\ ${ }^{\mathrm{c}}$ Laboratory for Imaging Algorithms and Systems, Rochester Institute of Technology \\ ${ }^{\mathrm{d}}$ Carnegie Airborne Observatory, Department of Global Ecology, Carnegie Institution for Science \\ ${ }^{\mathrm{e}}$ MERAKA. Council for Scientific and Industrial Research \\ (jolenefisher@gmail.com, Barend.Erasmus@wits.ac.za, Ed.Witkowski@wits.ac.za, vanaardt@.cis.rit.edu, gpa@stanford.edu, \\ tbowdoin@stanford.edu, dknapp@standford.edu, RMathieu@csir.co.za, kwessels@.csir.co.za)
}

\begin{abstract}
Factors influencing woody savanna vegetation structure across a land-use gradient of intensity (highly and lightly utilized communal rangeland) and type (national protected area, private game reserve and communal rangelands) were investigated. Smallfootprint discrete return LiDAR data (1.12 $\mathrm{m}$ point spacing) from the Carnegie Airborne Observatory (CAO) 'Alpha system' were used to measure three-dimensional vegetation structure across the different treatments. A volumetric pixel (voxel) approach was used to characterise the vertical distribution of LiDAR returns, i.e., vegetation density, in one metre increments for comparison using descriptive statistics across the land-use type and intensity gradient. Vegetation structure in the national protected area was most similar to the lightly utilized rangelands, and the private game reserve was most similar to the highly utilized rangelands with low levels of structural diversity present. Current trends in structural diversity can be related to harvesting, regeneration, herbivory and fire.
\end{abstract}

Index Terms - LiDAR, vegetation density, land-use, 3-D vegetation profile, rangelands, protected areas

\section{INTRODUCTION}

Unsustainable resource use and land degradation is a key problem in sub-Saharan Africa, especially in rural areas where communities rely directly on ecosystem goods and services. In spite of the obvious urgency to address unsustainable land-use practices, there has been very few integrated studies over large areas on the relative importance of different factors and drivers, social and ecological, that affect and determine the ability of a landscape to deliver critical ecosystem goods and services.

Savanna ecosystems are characterised by the dynamics between trees and grass, as mediated by variation in fire regime, rainfall, soil type and herbivory. Resource extraction by people can be modelled as an extreme form of herbivory that will lead to a specific vegetation structure, mediated by fire, rainfall and soils. Combined with knowledge on the tree population dynamics, the nature of the vegetation structure can inform the sustainability of resource extraction. Previous studies either measured vegetation structure with a limited vertical resolution, and/or did so over small spatial extents. Small spatial extents will not capture the variability in resource extraction patterns due to historical factors [2], and will not be representative of landscape-level variation.

We identified two land-use types (protected areas and communal rangelands) and two land-use intensities (highly and lightly utilized communal rangelands) in the Lowveld region of South Africa. The sites provide a natural experiment to study the effects of various abiotic (geology, topography) and biotic factors (fire, herbivory, fuel wood harvesting) on vegetation structure. The effect of land-use on biodiversity has been shown for both compositional diversity and structural diversity, with diversity being highest at intermediate levels of disturbance [4, 13, 15]. Previous studies have been based on field data alone, typically sampling vegetation from less than 10 ha across the study site in question. New advances in remote sensing allow us to establish the effects of land-use on vegetation structure at large extents, while still obtaining the fine scale results published from field studies. Small footprint LiDAR data allows for the three-dimensional characterisation of vegetation structure at high resolution $(1.12 \mathrm{~m}$ point spacing). Although geology and topography play a key role in determining savanna vegetation structure (bottom-up controls) $[3,4,13]$ we control for this variation through careful site selection, and focus on the potential effects of top down ecosystem controls (fire, herbivory and resource extraction.). The aim of this investigation therefore was to establish the effects of land-use type and intensity on three-dimensional woody vegetation structure at a large scale and extent using small footprint, discrete return LiDAR data.

\section{METHODS}

\subsection{Study area}

The Bushbuckridge region (BBR) (communal rangelands), Sabi Sands Wildtuin (SSW) (private game reserve) and Kruger National Park (KNP) (state-owned conservation area) form a west to east land-use type gradient which is similarly characterised by a west to east gradient in climate, topography and land-use intensity of the communal rangelands. Mean annual precipitation over the study area ranges from $>1200 \mathrm{~mm}$ in the west, falling to an average of $550 \mathrm{~mm}$ in the east, with a mean annual temperature of $22^{\circ} \mathrm{C}$. The geology of the region is dominated by granite, with Timbavati gabbro intrusions. The region falls within three vegetation types of 
the savanna biome: granite lowveld (dominant), gabbro grassy bushveld and legogote sour bushveld [11].

The BBR consists of two former apartheid era homelands, Gazankulu and Lebowa [14], which were formed with the Natives Land Act (No. 27) of 1913. Between 1972 and 1994 human population density increased in the area to approximately 300 people $/ \mathrm{km}^{2}$, with resulting increase in land utilization intensity and economic impoverishment [10, 7]. Historically, cultural values of the people in the area prevented fuel wood harvesting from trees considered important for medicinal, food and cultural purposes; however, the high demand for fuel wood and timber, together with a weakening of traditional authority associated with participation in democratic elections in 1994, now overrides these values in many areas [4].

Sabi Sand Wildtuin (SSW) is 65000 ha in size and was only formally proclaimed in 1965. From 1922 until 1934 the area was known as the Sabie Ranch, owned by the Transvaal Consolidated Lands (TCL), and was used for cattle farming [16]. Currently, SSW has a strong tourism-based approach to conservation management.

Kruger National Park was proclaimed a national protected area in 1926 with the passing of the National Parks Act, and currently spans $22000 \mathrm{~km}^{2}$ [8]. Initial management of the reserve was aimed at the recovery of animal populations from the previous excessive meat and ivory hunting, and the rinderpest pandemic at the end of the $19^{\text {th }}$ century. Current management has clear research and management objectives, intending "to maintain biodiversity in all its natural facets and fluxes and to provide human benefits in keeping with the mission of SANParks in a manner which detracts as little as possible from the wilderness qualities of the Kruger National Park" [8].

\subsection{Light Detection and Ranging (LiDAR)}

In April 2008 LiDAR data were collected by the Carnegie Airborne Observatory (CAO) over the study area, covering approximately 35000 ha. The work reported here is a subset of a larger project to compare landscapes with different land-uses. From the 35000 ha, sites were selected to control for the effects of geological substrate and topographical position (equal areas of granite and gabbro, and crests and lowlands were sampled). The CAO Alpha system comprises in-flight fusion of imaging spectroscopy and LiDAR allowing for mapping of threedimensional canopy structure and shape. The LiDAR data were collected at $2000 \mathrm{~m}$ a.g.1 with a laser pulse repetition frequency of $50 \mathrm{kHz}$ and laser point spacing of $1.12 \mathrm{~m}$. The integrated GPSIMU sub-system in the $\mathrm{CAO}$ ensures accurate and precise projection and mapping of the data [1].

\subsubsection{Ground validation}

We conducted field surveys concurrently with the flight campaign to assess the accuracy of the CAO LiDAR height estimates. In total, 883 trees between one and $15 \mathrm{~m}$ in height, of a wide range of common species, were sampled. Maximum tree heights were measured using either a graduated range pole, a laser rangefinder (TruPulse $\mathrm{TM}^{\mathrm{TM}} 360^{\circ}$ B) or a Vertex hypsometer. Either Trimble (Trimble ${ }^{\circledR}$ Recon ${ }^{\circledR}$ Handheld with ProXRS antenna) or Leica (GS20 Professional Data Mapper with handheld antenna) differential GPS's were used to collect accurate geographic coordinates, which we then differentially corrected to sub-meter accuracy using the Nelspruit trigonometric base station one second data [17]. We plotted the co-ordinates of each tree on the LiDAR derived vegetation canopy model (1.12 m resolution) and then used linear regression to compare the LiDAR derived tree heights with the field measured heights.

\subsubsection{Vegetation structural analysis}

A volumetric pixel (voxel) -based LiDAR approach was used to extract the vertical vegetation height profiles. The raw laser point cloud was divided into volumetric pixels $(5 \mathrm{~m}$ horizontal resolution, $1 \mathrm{~m}$ vertical resolution) based on the frequency of laser returns for each spatial volume. We then randomly sampled 200 ha in each study area, sampling equally in each land-use type and intensity, on both geological substrates (granite and gabbro) and topographical positions (crests and lowlands). We extracted the vertical vegetation density profiles from the LiDAR data, using the mean percentage laser returns at each height (in one metre increments) within the 200 ha sample, which gives a measure of vegetation density at that height. The profiles were compared using the variance and kurtosis of the vegetation density at each height.

\section{RESULTS}

\subsection{Ground validation}

LiDAR derived vegetation heights showed a strong positive relationship with field measure vegetation heights with $\mathrm{r}^{2}=0.93$ at $\mathrm{p}<0.0001$. We therefore used the LiDAR derived measurements without applying any corrections.

\subsection{Land-use type}

The first comparison is between protected area land-uses (SSW and KNP combined) and the rural rangelands. The majority of tree LiDAR returns in the protected areas occurs between two and five metres, whilst the majority of returns in the rangelands is below three metres (Fig. 1). Below $2 \mathrm{~m}$ vegetation density is higher in the rangelands.

Within the protected area land-use type, there were differences between SSW and KNP. The majority of vegetation in KNP occurs between $2-5 \mathrm{~m}$, with an extreme peak from $3-4 \mathrm{~m}$, and little vegetation below $2 \mathrm{~m}$ (Fig. 2a). Sabi has a more even distribution of vegetation throughout the vertical profile, showing similar trends to KNP except with a less extreme peak from $3-4$ $\mathrm{m}$, and slightly more vegetation below $2 \mathrm{~m}$ and above $5 \mathrm{~m}$ than KNP (Fig. 2b).

\subsection{Land-use intensity}

The lightly utilized rangelands contain the most vegetation below 3 $\mathrm{m}$ compared to all other land-use types and intensities (Fig. 2c). The highly utilized rangelands have the lowest number of discrete LiDAR returns than all other sites, and the vegetation is distributed evenly throughout the vertical profile (Fig. 2d). This shows that not only is there little vertical structural differentiation, but the overall vegetation density is the lowest. 


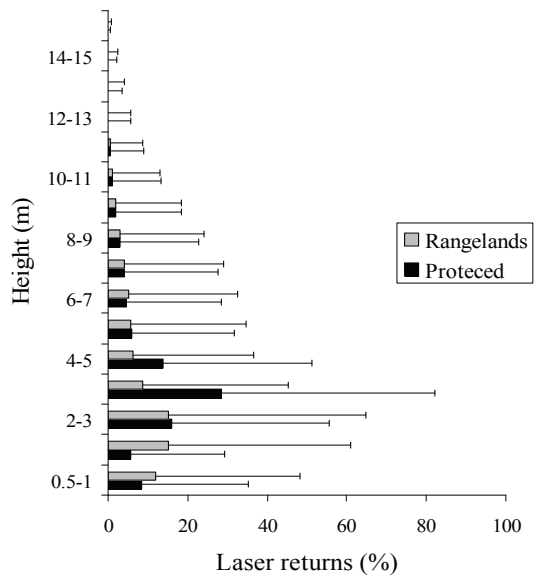

Figure 1: Vertical distribution of vegetation density in the protected areas (Kruger National Park and Sabi Sands Wildtuin study areas) and the communal rangelands (near the towns of Justicia and Kildare, Bushbuckridge) in South Africa. Percentage laser returns refers to the mean of all laser returns in a 200 ha sample area in a specific height class. Error bars indicate standard deviation.

\section{DISCUSSION}

The vertical distribution of foliage within the vegetation profile does appear to be influenced by both land-use type and intensity. The differences in vegetation density between the protected areas and rangelands occur at ecologically meaningful heights. Most fuel wood is collected at heights which are easy to reach, usually below three metres [9]. Harvesting wood causes these trees to coppice which explains the high vegetation density below three metres (Fig. 1 and Fig. 2c). The lack of vegetation density above this height is possibly due to high harvesting pressure which prevents vegetation growing tall, similar to vegetation being kept in a browsing- or fire trap. This coppice layer of trees remains reproductively inactive, resulting in reduced recruitment, and an even lower probability of recruitment into higher height classes. The few trees that have survived into higher height classes, are mostly due to species-related cultural traditions that exempt them from utilisation that alters structure. These results are confirmed by previous field-based studies finding the majority of trees less than or equal to $1.5 \mathrm{~m}$ in height $[4,12]$. The protected areas have less vegetation in the lower height classes (Fig. 1), possibly due to higher browsing pressure, and less whole-stem removal that lead to coppicing. This leads to a higher likelihood of recruitment into higher height classes and it would explain the higher vegetation density between three and five metres (Fig. 1 and Fig. 2a \& 2b). In the rangelands however, although trees are allowed to coppice, they are re-harvested before they can reach higher height classes.

Similar patterns, due to historical land-use change, can be seen when the two protected areas are compared. The vegetation density in both KNP and SSW is highest between two and five metres, although the vertical distribution of vegetation is more even in SSW (Fig. 2a \& 2b). Sabi Sands was proclaimed as a game reserve more recently than KNP [6] and has also had a longer history of cattle farming. Vegetation in areas not used for cattle was allowed to grow tall, which may explain the occurrence of more tall trees in SSW, and potentially the higher amount of vegetation below three meters in SSW is due to bush encroachment

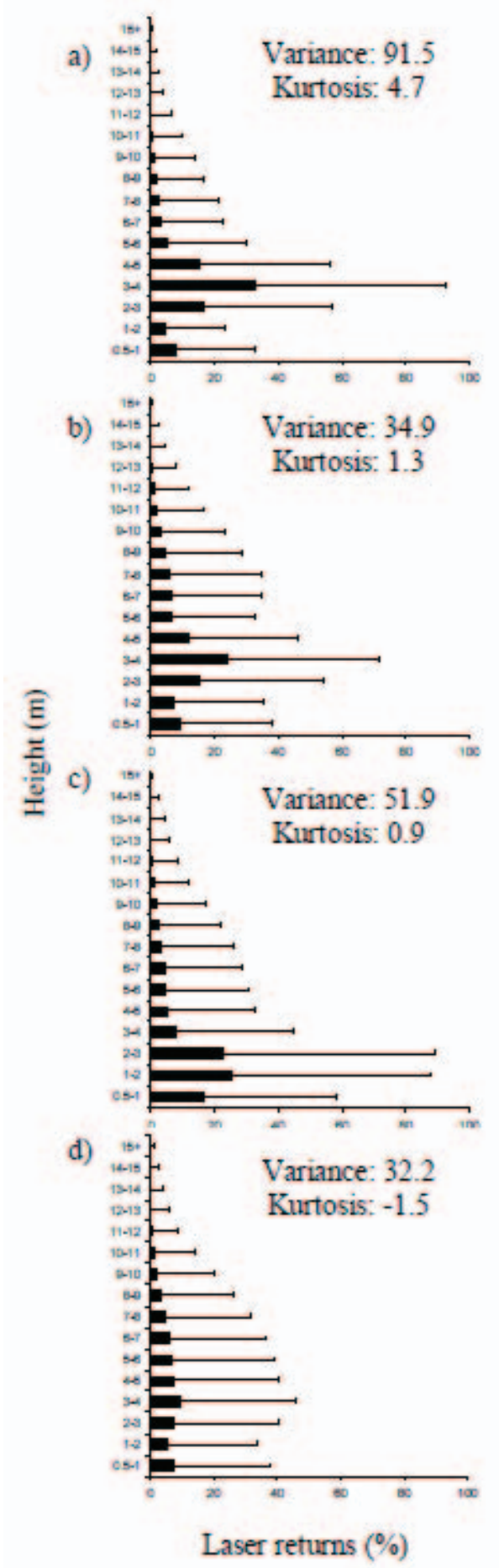

Figure 2: Vertical distribution of vegetation density in 200 ha a) Kruger National Park, b) Sabi Sands Wildtuin, c) moderately utilized rangelands in Bushbuckridge and d) highly utilized rangelands in Bushbuckridge. Percentage laser returns refers to the mean of all laser returns in a 200 ha sample area in a specific height class. Error bars indicate standard deviation. 
in previously overgrazed areas. Elephant densities in SSW have also been lower than that of Kruger until 1993 when the fence between the reserves was removed [5].

The lightly utilized rangelands show high vegetation density below three metres, possibly due to regeneration after harvesting, however it is unclear if recruitment is taking place as well, a factor which still needs to be investigated. The vegetation above five metres is comparable to SSW (Fig. 2b \& 2c). Certain culturally important trees such as Sclerocarya birrea grow tall and are not harvested for wood; instead they are used for shade and fruit. Unfortunately the need for fuel wood is beginning to override the cultural importance [4] with the increase in population density [7] as is seen in the highly utilized rangelands where there is little vegetation in all height classes compared to the other sites (Fig. 2d). Vegetation in the highly utilized site is diminished throughout the vegetation profile due to high harvesting pressure of existing tall trees, and the continued coppiced state of smaller trees.

These results present the state of vegetation structure at one point in time and therefore do not shed light on short-term dynamics. However, the structural response of vegetation to different types of utilisation (browsing, grazing, harvesting) is well-known in savannas, and therefore inferences on the sustainability trajectory based on structure in different land-uses remain informative, even if only as a baseline for future studies. This is an ongoing study, and future work on waveform LiDAR for fine-scale vegetation structure, more in-depth analyses of historical land-use through interviews and a repeat LiDAR campaign in 2010 will contribute significantly to firm up the provisional results reported here.

\section{ACKNOWLEDGEMENTS}

We would like to thank Russell Main, Laven Naidoo, Puli Nkoana, Moses Cho, Pat Dwyer, Bongani Majeke and Chris Munyati for help in the field. The Carnegie Institution for Science is thanked for help with image analysis. We acknowledge the Andrew Mellon Foundation, W.M. Keck Foundation and William Hearst III for supporting the Carnegie Airborne Observatory and funding the imagery. Izak Smit and SANParks staff helped with logistics in Kruger.

\section{REFERENCES}

[1] Asner, G.P., Knapp, D.E., Kennedy-Bowdoin, T., Jones, M.O., Martin, R.E., Boardman, J. and Field, C.B., "Carnegie Airborne Observatory: in-flight fusion of hyperspectral imaging and waveform light detection and ranging (wLiDAR) for threedimensional studies of ecosystems." J. App. Remote Sens. 1, 013536 pp. 1-21, 2007

[2] Giannecchini, M, Twine, W. and Vogel, C. "Land-cover change and human-environment interactions in a rural cultural landscape in South Africa." Geogr. J. 173(1), pp. 26-42, 2007

[3] Gillson, L., "Evidence of hierarchical patch dynamics in an east African savanna." Landscape Ecology 19(8), pp. 883-894, 2004

[4] Higgins, S.I., Shackleton, C.M. and Robinson, E.R., "Changes in woody community structure and composition under contrasting landuse systems in a semi-arid savanna, South Africa." $J$. Biogeogr. 26, pp 619-627, 1999
[5] Hiscocks, K., "The impact of an increasing elephant population on the woody vegetation in southern Sabi Sand Wildtuin, South Africa." Koedoe 42(2), pp. 47-55, 1999

[6] Joubert, S., The Kruger National Park - A History, Volume 1. High Branching Pty(Ltd), Johannesburg, South Africa, pp.1-36, 2007

[7] Kirkland, T., Hunter, L.M. and Twine, W., ““'The bush is no more": Insights on institutional change and natural resource availability in rural South Africa." Soc. \& Nat. Resources 20: pp. 337-350, 2007

[8] Mabunda, D., Pienaar, D.J. and Verhoef, J., "The Kruger National Park: A century of management and research." In: du Toit, J.T., Rogers, K.H. and Biggs, H.C. (Eds.) "The Kruger experience: ecology and management of savanna heterogeneity." Island Press Washington, DC. pp. 3-21, 2003

[9] Neke, K., "Woody plant allometry and demography in a semiarid Africa savanna. The regeneration ecology of savanna woodlands in relation to human utilization." $\mathrm{PhD}$ thesis. University of the Witwatersrand, South Africa, 2004

[10] Pollard, S., Shackleton, C. and Carruthers, J., "Beyond the fence: people and the Lowveld landscape." In: du Toit, J.T., Rogers, K.H. and Biggs, H.C. (Eds.) The "Kruger experience: ecology and management of savanna heterogeneity." Island Press Washington, DC. pp. 3-21, 2003

[11] Rutherford, M.C., Mucina, L., Lötter, M.C., Bredenkamp, G.J., Smit, J.H.L., Scott-Shaw, C.R., Hoare, D.B., Goodman, P.S., Bezuidenhout, H., Scott, L., Ellis, F., Powrie, L.W., Siebert, F., Mostert, T.H., Henning, B.J., Venter, C.E., Camp, K.G.T., Siebert, S.J., Matthews, W.S., Burrows, J.E., Dobson, L., van Rooyen, N., Schmidt, E., Winter, P.J.D., du Preez, P.J., Ward, R.A., Williamson, S. and Hurter, P.J., "Savanna Biome." In: Mucina, L. and Rutherford, M.C. (Eds.) "The vegetation of South Africa, Lesotho and Swaziland.' Strelitzia 19. South African National Biodiversity Institute, Pretoria, pp. 439-539, 2006

[12] Shackleton, C.M., Griffen, N.J., Banks, D.I., Mayrandonis, J.M. and Shackleton, S.E., "Community structure and species composition along a disturbance gradient in a communally managed South African savanna." Vegetatio 115, pp. 157-167, 1994

[13] Shackleton, C.M., "Comparison of plant diversity in protected and communal lands in the Bushbuckridge Lowveld savanna, South Africa." Biol. Conserv. 94, pp. 273-285, 2000

[14] Thornton, R., "Environment and land in Bushbuckridge." http://hdgc.epp.cmu.edu/misc/BushbrSA2.pdf, 2002

[15] Vermeulen, S.J., "Cutting of trees by local residents in a communal area and an adjacent state forest in Zimbabwe." Forest Ecol. Manag. 81, pp. 101-111, 1996

[16] http://www.sabisands.co.za/

[17] http://www.trignet.co.za/ 